\title{
Evaluation of Improvement Actions Impact on Manufacturing Operational Performance
}

\author{
Cátia Barbosa ${ }^{1}$, Américo Azevedo $^{1,2}$ \\ ${ }^{1}$ Faculty of Engineering, University of Porto, Porto, Portugal \\ ${ }^{2}$ Inesc TEC, Porto, Portugal \\ (up201409940@fe.up.pt)
}

\begin{abstract}
Due to the current demands from the market, technological improvements and action of competitors, manufacturing companies are pushed to compete in shorter product development cycles. This poses a great challenge, as the conventional product development cycle is shortened. Hence, companies are forced to introduce some improvement action plans and adopt certain manufacturing operational strategies to remain competitive and achieve a good market share. Due to the importance of this topic, in this paper we revise the current manufacturing improvement plans in the literature, to establish the basis of our future research work. The findings of this work point towards the need to develop a system that integrates the evaluation of the manufacturing improvement plans in the future overall performance of the manufacturing plant and aid in the process of decision-making.
\end{abstract}

Keywords - Complexity, Manufacturing, Performance, Product life cycle

\section{INTRODUCTION}

Currently, organizations are receiving a higher push to offer products that more reliable, with more features, at lower prices [1], and a larger product portfolio [2]. The users' needs are the drivers for product design and manufacturing. However, due to differences among users, it becomes necessary to create a great variety of products [3]. The increased product variety as demanded by the market is one of the main drivers of manufacturing complexity $[2,4]$.

Complex manufacturing systems are difficult to define [5]. The complexity of manufacturing systems appears under a variety of aspects [6], and resides in the high number of parts that constitute these systems, as well as the rarely simple relationships amongst these parts [5]. The complexity of the manufacturing systems results from the great number of products, the variability in the product mix, the multiplicity of involved processes, and the actions from external agents [7]. In fact, the high complexity in manufacturing systems is a consequence of the social and technical systems interaction [8].

There are three main variants that were identified in the literature as the origin of manufacturing systems complexity: product, processes and operations and systems [9-11]. The linkage among parts in a manufacturing system affects complexity. The more complicated the products, processes and manufacturing systems, the higher is the cost of design, implementation, planning, operations and control. Therefore, it is needed a trade-off between simplicity and complexity and the effects on competitiveness and profits [12]. Industries as electronics, semiconductor, aerospace and automotive are highly complex [13].

The fast technology development and the high competition among companies lead to reduced product life cycles. Hence, companies face the challenge of adapting and creating an effective planning for their facilities to be useful for a period of time longer than the life cycle of the individual products they are producing [14]. The reduced product life cycles tend to increase the importance of competing in the product development cycle time [15]. Therefore time-to-market appears as a crucial competitive factor for companies through all markets. Companies achieving shorter product development cycles can achieve higher market share. and profits [16]. The framework in Fig.1 summarizes these interactions of the manufacturing companies, markets, competitors and internal actions.

Considering that the manufacturing environment is rapidly and constantly changing, with higher levels of customization and complexity, there is higher demand for flexibility and adaptability from companies [17, 18]. Flexibility in manufacturing systems provides advantages as higher product quality, reduced lead times, and reduced work-in-progress, among others [19].

The conventional life cycle of a product is divided in four stages: introduction, growth, maturity and decline. Sales are very much reduced in the introduction stage; when the investments are paid, the product moves to the growth stage; when there is a slowdown in sales, the product enters in the maturity phase, and finally ends in the decline stage, with a possible sales decrease [20]. With the reduced product's life cycle, the product life cycle curve has to move to right, as in Fig.2, meaning that the time to introduce a product to the market and develop it is much more reduced, and the slow-growing curve slope of introduction and growth stages has to be much higher, so the product achieve acceptable sales faster.

This poses a major question regarding the methodologies, tools and strategies that are being employed by companies to evaluate the performance impact of their improvement actions in the manufacturing environment. Hence, our future research question is:

RQ: How can companies assess the effect of operational strategies (e.g. action plans) on future operational performance? 


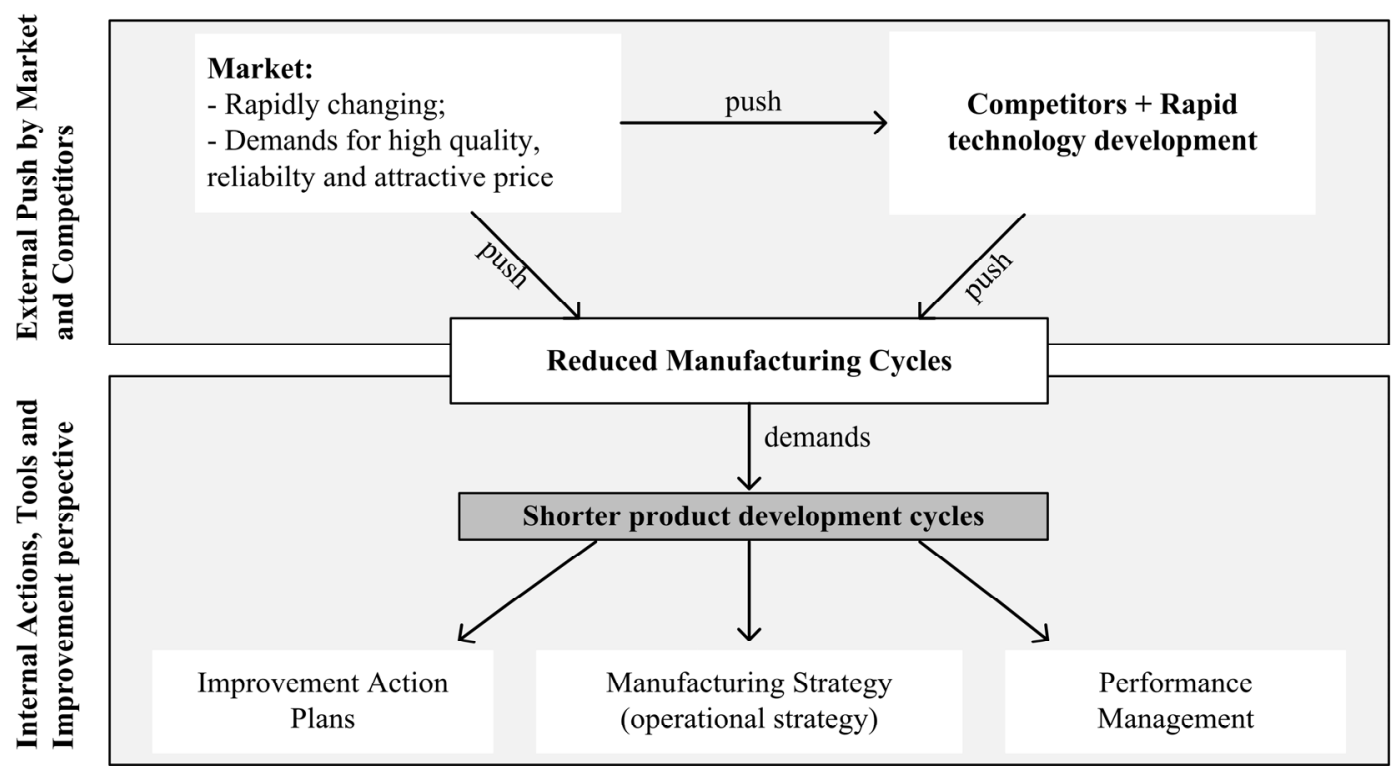

Fig. 1. Framework for the interactions of the manufacturing companies, markets, competitors and internal actions.

At this preliminary stage of our study, we aim at understanding the main practices and tools that have been used throughout time to manage the reduction in the product's life cycle and the impact of those strategies in the manufacturing plant. To achieve this, we performed a literature research, using important scientific databases (e.g. Scopus, Science Direct, Emerald Insight, Taylor \& Francis Online, among others).

The remaining of the paper is organized as follows. Section II includes a review about manufacturing improvement actions that have been reported in literature and their impact in the manufacturing plant; and section III provides the most important conclusions retrieved from the literature research and the future research directions we will be following in the future.

\section{IMPROVEMENT ACTIONS AND IMPACT ON THE MANUFACTURING PLANT}

It is very difficult to predict the effects that decisions and actions in the manufacturing environment, will have in the future systems performance. This is due to the dynamism in manufacturing that increases the number of decisions that need to be made [8]. Good manufacturing systems performance is highly dependent on an efficient design, planning and scheduling on a real-time running system [21].

Organizations achieve their goals by satisfying their customers more effectively and more efficiently than their competitors. For this, the performance level of an organization is a function of efficiency and effectiveness of the actions it adopts [22]. The speed, flexibility and quality with which a company serves its customers, measured against the capacity to balance the demand, the manufacturing capacity and the supply, gives the performance of a manufacturing organization. By modelling the system dynamics, the operation of the manufacturing facility can be understood and simplified, and waste in the process can be eliminated [2].

Performance indicators for manufacturing systems are unpredictable. In [23], the authors identified a set of four manufacturing performance indicators: cost, time, quality and flexibility. The authors proposed a method to analyze the complexity of a manufacturing system, considering the unpredictable nature of the performance indicators. The unpredictable behavior of the performance indicators was analyzed from a time series perspective, using the complexity measure of the Kolmogorov Lempel Ziv.

The design of flexible manufacturing systems is very complex. It must consider many criteria, as cost, production, flexibility, among others. Taking this into consideration, Borenstein, Becker and Santos [24] proposed a method to analyze the flexible manufacturing systems design, using integrated, systemic, global and user-centered approach. This approach introduced a successful method to incorporate the company's strategy during the stage of design of flexible manufacturing systems. Additionally, in [25] was presented a framework methodology to develop complex flexible manufacturing

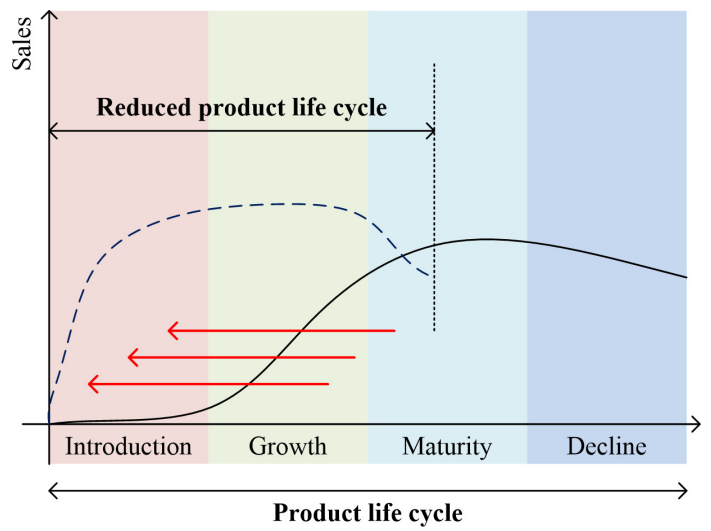

Fig. 2. Conventional product life cycle and reduced product life cycle, as demanded by markets and technological development. 
systems, including the simulation of system behavior.

Industrial enterprises face the challenge to deal with complexity and uncertainty, being manufacturing strategy of major importance to cope with these [26]. However, the manufacturing strategy formation is a very complex process that needs to consider deliberate and emergent decisions and actions [27]. Due to the uncertainty generated by complexity, several authors have claimed that complexity reduction should be one of the goals of operations $[19,28]$, as less complex systems have proved to be more efficient and robust, and because productivity drops as systems become more complex $[10,19]$.

Some common initiatives were taken for enhancement of manufacturing processes. Some examples of these initiatives include: 5S, lean thinking, Six Sigma, total quality management [1], zero defects, just-in-time, manufacturing lead time reduction [29]. However, the impact of these manufacturing practices has not been clearly understood, and a study [29] showed that there is not a straightforward relationship amongst manufacturing improvement programs and actions and manufacturing performance.

Nowadays it is very important that firms are able to organize their performance management. For companies engaged in a continuous improvement philosophy, a very common tool to be used is the PDCA (Plan-Do-CheckAct) cycle, first introduced by Deming. In [30] the authors concluded that the PDCA cycle can be an effective tool to better manage performance.

Furthermore, Berrah, Mauris and Montmain [31] considered the few quantitative approaches in literature of Performance Measurement Systems (PMSs) as a motive to further develop a model using a Choquet integral aggregation operator. Their proposed model intended the monitoring of the continuous improvement action plans, to help managers to continuously improve the performance of their firms, as well as more effectively distribute resources to achieve a desired level of performance.

When conducting a study on the data retrieved from the third International Manufacturing Strategy Survey, the authors in [32] found that companies that had an official manufacturing strategy with clearly defined competitive priorities, improvement action plans and programs where much better aligned than those companies that did not present a clear strategy. Companies that clearly establish a manufacturing strategy are more successful in translating competitive priorities in manufacturing improvement and action programs. The manufacturing strategy is usually more or less formally defined; however, some decisions performed by managers are emergent. Even though the translation of competitive priorities into improvement programs is successful for companies with a defined manufacturing strategy, those manufacturing action programs also limit competitive priorities.

Delayed product differentiation has been pointed as a means of reducing manufacturing complexity and accomplishing competitive advantage in the market. This included the postponing of the stages at which product varieties and differentiation appeared in the manufacturing systems [4].

In order to understand customers' satisfaction level and areas in the organization with room for improvement, Yang [33] used customers' satisfaction survey. Continuous improvement actions were found to make possible the increase in customers' satisfaction and profits. The author claimed that with the information retrieved from the customers' satisfaction survey and by deducing and using an optimization theory inside a company, it becomes possible the focusing on optimal conditions and identification of the critical attributes that need to be improved.

Kim and Arnold [34] developed a model for manufacturing strategy development in order to connect the competitive priorities of the organization with the decisions and action programs that have to be developed. It was observed that when a company had its competitive priorities focused on a determined goal, manufacturing objectives and action plans were pointed to a certain direction, to meet that goal.

It is very important that companies identify their improvement priorities. For this reason, Barad and Gien [35] developed a framework to aid in determining the improvement priorities of small and medium enterprises, by approaching a process very similar to the manufacturing strategy formation. The authors proposed the successful use of quality function deployment in their framework to understand the needs from customers and translate those needs into improvement targets.

Assuming that the best performing companies are those that employ the best manufacturing practices, in [36] was performed a study on the highest performing firms of the 2002 International Manufacturing Strategy Survey database to identify those best practices. On one hand, the best practices that were identified corresponded to the high focus on the process, pull production, the productivity of equipment and environmental concerns. On the other hand, quality management was found not to be very relevant amongst the best manufacturing practices.

The study performed by Swink, Narasimhan and Kim [37] advanced the theory that practices affect performance through the integration of strategy and manufacturing capabilities as cost and flexibility. Their conclusions state that when integrating strategy there is more efficiency in terms of cost and product flexibility. Additionally, the integration of strategy allows better development of products and processes, supplier relationship, workforce growth, just-in-time flow, among others.

\section{CONCLUSIONS AND FUTURE RESEARCH DIRECTIONS}

The contribution of this paper to the literature of the improvement actions performed in the context of manufacturing companies resides in the gathering of information regarding recurrent improvement practices and plans employed by managers. This is particularly 
relevant because different improvement have very different results on the complex manufacturing systems performance.

Amongst the commonly referred actions to improve manufacturing performance are: the alignment of actions in the manufacturing plant with competitive priorities, the continuous improvement actions, quality function deployment, environmental concerns, the delayed product differentiation, lean manufacturing, and the PDCA cycle.

Manufacturing strategy is very complex and dependent on several factors. This is a consequence of the volatility of expectations and demands from the market and from the constantly improving technology and actions performed by the competitors. Moreover, the fact that the manufacturing plant needs to be constantly adapting to the new requirements induced by the introduction of new products and product variants, adds the need for flexibility. One of the strategies that have been pointed as a good mean of controlling the systems actions is the modelling of system dynamics.

There is high unpredictability in performance indicators on manufacturing companies. Hence, the degree of difficulty in accurately understanding the impact that manufacturing decisions and improvement plans have on performance is aggravated.

As it would be expected, all the decisions performed in the manufacturing companies influence the level of performance achieved. As it is very difficult to understand the impact that certain decisions have on the future performance, it becomes even harder to make the necessary decisions with safety. Even though some works have been found in literature focusing on the impact that manufacturing choices and complexity have on the plant performance, this research area appears as still having great room for improvement, especially in what concerns to understanding the impact that product complexity has on performance, or predicting the success or failure of a product; but also in understanding the impact that the operations strategy and the processing environment have on the overall performance.

One of the drawbacks we found on the currently available literature resides in the lack of practical application of the frameworks developed by the authors and their consequent performance evaluation. This opens a research branch to be explored, with the need to proceed

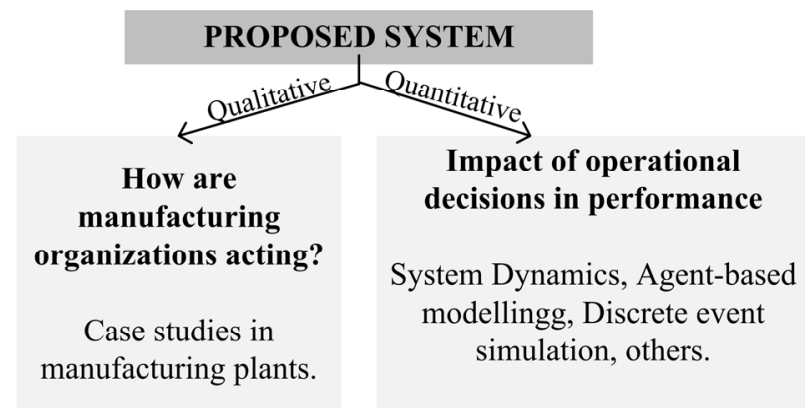

Fig. 3. Framework that serves as guide in the work to be developed. to the real application of the theoretical frameworks, to better understand their effectiveness and value.

Our future research directions are pointed towards answering the research question introduced in this paper. To achieve our goal, we plan on using a hybrid approach, with qualitative and quantitative methods. This will allow the evaluation of the operational choices in the real manufacturing environment, and the quantification of the impact that those choices have in the overall performance. The qualitative evaluation of the system will make use of case studies in complex manufacturing systems, which will allow an understanding the most recurrent operational actions performed in these environments. The quantitative part of the method to be developed will make use of the modelling of the system's dynamics, to better understand the nonlinear behavior of the systems. However, the system dynamics looks at the system with a very broad perspective. To overcome this shortcoming, we intend on also using agent-based modelling to better understand the complexity of the interactions developed among agents in the manufacturing environment. Discrete event simulation will also be used to have an insight about the most relevant alterations that occur in the system from one event to the other. Other tools might as well be useful during the project, as neural networks or support vector machines. This tool we intend on developing will allow managers to act faster and more efficiently. Fig. 3 shows the framework to be followed in the current work development.

\section{ACKNOWLEDGMENT}

The authors acknowledge the funding of $\mathrm{PhD}$ scholarship PD/BD/105988/2014, through the Portuguese funding agency, FCT - Fundação para a Ciência e a Tecnologia.

\section{REFERENCES}

[1] A. Tiwari, K. Younis, C. Turner, P. Sackett, and M. C. Bautista, "Capturing and evaluating process information for high-performance complex manufacturing operations," Journal of Manufacturing Technology Management, vol. 21, pp. $585-603,2010$.

[2] T. Tahmassebi, "Issues in the management of manufacturing complexity," Computers and Chemical Engineering Supplement, pp. 907-910, 1999.

[3] H. ElMaraghy, G. Schuh, W. ElMaraghy, F. Piller, P. Schonsleben, M. Tseng, et al., "Product variety management," CIRP Annals - Manufacturing Technology, vol. 62, pp. 629-652, 2013.

[4] J. Ko and S. J. Hu, "Balancing of manufacturing systems with complex configurations for delayed product differentiation," International Journal of Production Research, vol. 46, pp. 4285-4308, 2008.

[5] L. D. Fredendall and T. J. Gabriel, "Manufacturing Complexity: A Quantitative Measure," presented at the POMS Conference, Savannah, GA, 2003.

[6] M. Cantamessa, "The manufacturing system as a complex artifact," Robotics and Computer-Integrated Manufacturing, vol. 14, p. 403-414, 1998. 
[7] L. Monch, "Simulation-based benchmarking of production control schemes for complex manufacturing systems," Control Engineering Practice, vol. 15, pp. 1381-1393, 2007.

[8] Z. Zhang, "Modeling complexity of cellular manufacturing systems," Applied Mathematical Modelling, vol. 35, pp. 4189-4195, 2011.

[9] W. H. ElMaraghy and R. J. Urbanic, "Modelling of Manufacturing Systems Complexity," CIRP Annals Manufacturing Technology, vol. 52, pp. 363-366, 2003.

[10] N. P. Suh, "Complexity in Engineering," CIRP Annals Manufacturing Technology, vol. 54, pp. 46-63, 2005.

[11] P. Gullander, A. Davidsson, K. Dencker, A. Fasth, T. Fässberg, U. Harlin, et al., "Towards a Production Complexity Model that Supports Operation, Re-balancing and Man-hour Planning," in Proceedings of the 4th Swedish Production Symposium (SPS), Lund, Sweden, 2011.

[12] W. ElMaraghy, H. ElMaraghy, T. Tomiyama, and L. Monostori, "Complexity in engineering design and manufacturing," CIRP Annals - Manufacturing Technology, vol. 61, pp. 793-814, 2012.

[13] J. W. Fowler and O. Rose, "Grand Challenges in Modeling and Simulation of Complex Manufacturing Systems," The Society for Modeling and Simulation International, vol. 80, pp. 469-476, 2004.

[14] C. Gaimon and V. Singhal, "Flexibility and the choice of manufacturing facilities under short product life cycles," European Journal of Operational Research, vol. 60, pp. 211-223, 1992.

[15] J. D. Sherman, W. E. Souder, and S. A. Jenssen, "Differential effects of the primary forms of cross functional integration on product development cycle time," Journal of Product Innovation Management, vol. 17, pp. $257-267,2000$

[16] J. T. Vesey, "Time-to-market: Put speed in product development," Industrial Marketing Management, vol. 21, pp. 151-158, 1992.

[17] O. Kuzgunkaya and H. A. ElMaraghy, "Assessing the structural complexity of manufacturing systems configuration," International Journal of Flexible Manufacturing Systems, vol. 18, pp. 145-171, 2006.

[18] R. Fernandes, J. B. Gouveia, and C. Pinho, "Product mix strategy and manufacturing flexibility," Journal of Manufacturing Systems, vol. 31, pp. 301- 311, 2012.

[19] J. Sarkis, "An empirical analysis of productivity and complexity for flexible manufacturing systems," International Journal of Production Economics, vol. 48, pp. 39-48, 1997.

[20] C. Ryan and W. E. Riggs, "Redefining the product life cycle: The five-element product wave," Business Horizons, vol. 39, pp. 33-40, 1996.

[21] T. Guimaraes, N. Martensson, J. Stahre, and M. Igbaria, "Empirically testing the impact of manufacturing system complexity on performance," International Journal of Operations \& Production Management, vol. 19, pp. 1254 1269,1999

[22] A. Neely, M. Gregory, and K. Platts, "Performance measurement system design: A literature review and research agenda," International Journal of Operations \& Production Management, vol. 15, pp. 80 - 116, 1995.

[23] K. Efthymiou, A. Pagoropoulos, N. Papakostas, D. Mourtzis, and G. Chryssolouris, "Manufacturing systems complexity: An assessment of manufacturing performance indicators unpredictability," CIRP Annals - Manufacturing Technology, vol. 7, pp. 324-334, 2014.

[24] D. Borenstein, J. L. Becker, and E. R. Santos, "A systemic and integrated approach to flexible manufacturing systems design," Integrated Manufacturing Systems, vol. 10, pp. 6 14, 1999.

[25] H. Y. K. Lau and K. L. Mak, "The design of flexible manufacturing systems using an extended unified framework," Journal of Manufacturing Technology Management, vol. 15, pp. 222 - 238, 2004.

[26] J. O. Riis, J. Johansen, B. V. Waehrens, and L. Englyst, "Strategic roles of manufacturing," Journal of Manufacturing Technology Management, vol. 18, pp. 933 948, 2007.

[27] D. Barnes, "The complexities of the manufacturing strategy formation process in practice," International Journal of Operations \& Production Management, vol. 22, pp. 1090 $1111,2002$.

[28] G. Frizelle and E. Woodcock, "Measuring complexity as an aid to developing operational strategy," International Journal of Operations \& Production Management, vol. 15, pp. 26 - 39, 1995.

[29] A. D. Meyer and K. Ferdows, "Influence of Manufacturing Improvement Programmes on Performance," International Journal of Operations \& Production Management, vol. 10, pp. $120-131,1990$.

[30] D. Qing-ling, C. Shu-min, B. Lian-liang, and C. Jun-mo, "Application of PDCA Cycle in the Performance Management System," presented at the 4th International Conference on Wireless Communications, Networking and Mobile Computing, Dalian, 2008.

[31] L. Berrah, G. Maurisa, and J. Montmain, "Monitoring the improvement of an overall industrial performance based on a Choquet integral aggregation," Omega The International Journal of Management Science, vol. 36, pp. 340-351, 2008.

[32] N. Acur, F. Gertsen, H. Sun, and J. Frick, "The formalisation of manufacturing strategy and its influence on the relationship between competitive objectives, improvement goals, and action plans," International Journal of Operations \& Production Management, vol. 23, pp. 1114 - 1141, 2003.

[33] C.-C. Yang, "Improvement actions based on the customers' satisfaction survey," Total Quality Management \& Business Excellence, vol. 14, pp. 919-930, 2003.

[34] J. S. Kim and P. Arnold, "Operationalizing manufacturing strategy: An exploratory study of constructs and linkage," International Journal of Operations \& Production Management, vol. 16, pp. 45 - 73, 1996.

[35] M. Barad and D. Gien, "Linking improvement models to manufacturing strategies - a methodology for SMEs and other enterprises," International Journal of Production Research, vol. 39, pp. 2675-2695, 2001.

[36] B. T. Laugen, N. Acur, H. Boer, and J. Frick, "Best manufacturing practices: What do the best-performing companies do?," International Journal of Operations \& Production Management, vol. 25, pp. 131 - 150, 2005.

[37] M. Swink, R. Narasimhan, and S. Kim, "Manufacturing Practices and Strategy Integration: Effects on Cost Efficiency, Flexibility, and Market-Based Performance," Decision Sciences, vol. 36, pp. 428-457, 2005. 